THURSDAY, OCTOBER IO, I878

\section{THE ELECTRIC ARC AMONG THE GAS. SHARES}

IN Wednesday's Daily Neres we read as follows:-

"Gas shares have been subjected to considerable depreciation owing to the publication of some statements staied to have been made at a meeting in Birmingham. The folly which shareholders exhibit in sacrificing their holdings on the slightest alarm cannot be too strongly deprecated." Among the changes recorded in the official list we find Imperial Continental fell 7 ; Gas Light and. Coke, $\mathrm{H}$ issue, $7 \frac{1}{2}$; ditto, Ordinary, 5 , and so on, and so on.

There is little doubt that some excellent fooling (if fun were the writer's only object) on the part of the Nerv York Sun is among the causes of this wonderful exhibition of alarm on the part of gas shareholders. But we doubt the fun. Any man quoting the remark that the sun shines on the evil and the good, would, if he combined candour with perfect knowledge, make an exception in favour of the New York Sunz. It has a decided predilection for the evil. Nor is this all. Mr. Edison, besides being the most wonderful inventive genius of the age, is one of those rare beings, an American humourist. Indeed, if we are to believe the Western newspapers, those universities and stock raiscrs beyond Chicago who hastened, after the manner of our uwn Oxford, to enshrine his name on the rolls of their illustrious men and beasts, did so not because he had benefited mankind or lived laborious days in his laboratory at Menlo Park, but because a word dropped by him had given rise to the rumour that he had just put the finishing-touch to a swearing-machine.

Here is the New York Sun's story;---

"Mr. Edison says that he has discovered how to make electricity a cheap and practicable substitute for illuminating gas. Many scientific men have worked assiduously in that direction, but with little success. A powerful electric light was the result of these experiments, but the problem of its division into many small lights was a puzzler. Gramme, Siemens, Brush, Wallace, and others, produced at most ten lights from a single machine, but a single one of them was found to be impracticable for lighting aught save large foundries, mills, and workshops. It has been reserved for Mr. Edison to solve the difficult problem desired. This, he says, he has done within a few days. His experience with the telephone, however, has taught him to be cautious, and he is exerting himself to protect the new scientific marvel, which, he says, will make the use of gas for illumination a thing of the past.

"While on a visit to William Wallace, the electrical machine manufacturer in Ansonia, Connecticut, he was shown the lately-perfected dynamo-electric machine for transmitting power by electricity. When power is applied to this machine it will not only reproduce it but will turn it into light. Although said by Edison to be more powerful than any other machine of the kind known, it will divide the light of the electricity produced into but ten separate lights. These being equal in power to $4, \infty 00$ candles, their impracticability. for general purposes is apparent. Each of these lights is in a substantial metal frame, capable of holdingin a horizontal position two carbon plates, each 12 in. long, $2 \frac{1}{2}$ in. wide, and $\frac{1}{2}$ in. thick. The upper and lower parts of the frame are insulated from each other, and one of the conducting wires is connected with cach carbon. In the centre and above the upper carbon,

Vol. XVII, - -No. 467 is an electro-magnet in the circuit with an armature, by means of which the upper carbon is separated from the lower as far as desired. Wires from the source of electricity are placed in the binding posts. The carbons being brought together the circuit is closed, the electro-magnet acts, raising and lowering the upper carbon enough to give a bright light. The light moves towards the opposite end from which it starts, then changes and goes back, always moving towards the place where the carbons are nearest. together. If from any cause the light goes out the circuit is broken and the electric magnet ceases to act. Instantly the upper magnet falls the circuit is closed, it relights, and separates the carbon again.

"Edison on returning home after his visit to Ansonia studied and experimented with electric lights. On Friday last his efforts were crowned with success, and the project that has filled the minds of many scientific men for years was developed.

"'I have it now !' he said, on Saturday, while vigorously turning the handle of a Ritchie inductive coil in his laboratory at Menlo Park, 'and, singularly enough, I have obtained it through an entirely different process than that from which scientific men have ever sought to secure it. They have all been working in the same groove, and when it is known how I have accomplished my object, everybody will wonder why they have never thought of it, it is so simple. When ten lights have been produced by a single electric machine, it has been thought to be a great triumph of scientific skill. With the process I have just discovered I can produce I,000-ay, I0,000-from one machine. Indeed, the number may be said to be infinite. When the brilliancy and cheapness of the lights are made known to the public- - which will be in a few weeks, or just as soon as I can thoroughly protect the process-illiminiation by carburetted hydrogen gas will be discarded. With fifteen or twenty of these dynamo-electric machines recently perfected by Mr. Wallace, I can light the entire lower part of New York City, using a 500 horse-power engine. I purpose to establish one of these light centres in Nassau Street, whence wires can be run up town as far as the Cooper Institute, down to the Battery, and across to both rivers. These wires must be insulated, and laid in the ground in the same manner as gas-pipes. I also propose to utilise the gas-burners and chandeliers now in use. In each house I can place a light meter, whence these wires will pass through the house, tapping small metallic contrivances that may be placed over each burner. Then housekeepers may turn off their gas and send the meters back to the companies whence they came. Whenever it is desired to light a jet it will only be necessary to touch a little spring near it. No matches are required.

"'Again, the same wire that brings the light to you,' Mr. Edison continued, "will also bring power and heat. With the power you can run an elevator, a sewingmachine, or any other mechanical contrivance that requires a motor, and by means of the heat you may cook your food. To utilise the heat it will only be necessary to have the ovens or stoves properly arranged for its reception. This can be done at trifling cost. The dynamoelectric machine, called a telemachon, and which has already been described, may be run by water or steam power at a distance. When used in a large city the machine would of necessity be run by steam power. I have computed the relative cost of the light, power, and heat generated by the electricity transmitted to the telemachon to be but a fraction of the cost where obtained in the ordinary way. By a battery or steam-power it is forty-six times cheaper, and by water-power probably 95 per cent. cheaper.'

"It has been computed that by Edison's process the same amount of light that is given by I,000 cubic feet of the carburetted hydrogen gas now used in this way, and for which from $\$ 2.50$ to $\$ 3$ is paid, may be obtained for 
from 12 to 15 cents. Edison will soon give a public exhibition of his new invention."

So much for the New York Sun. Although a student of science will have little difficulty in associating the results promised with the discovery of perpetual motion, it is quite probable that Mr. Edison has actually succeeded in doing what he states he has done in his tele. gram: "I have just solved the problem of the sub-division of the electric light indefinitely." What we wish to point out is that it is one thing to do this and another thing to produce an electric light for ordinary house and street use. Once put the molecules of solid carbon in motion, and just because a solid is in question, the light must be excessive and the expenditure of energy must be considerable.

While it is easy to believe that the future may produce a means of illumination mid-way between the electric light and gas, it is equally easy to see that the thing is impossible without great waste, and therefore cost, with dynamo-electric machines and carbon poles. So long as carbon is employed we shall have much light which, perhaps, can be increased and steadied if various gases and pressures are tried. But streets and rooms full of such suns as these would be unbearable unless we sacrifice much of the light after we have got it. Split up the current in the manner so cheerfully described by the New York paper, and the carbon will refuse to flow altogether if an engine of 5,000,000 horse-power be employed instead of the modest one of 500 which is to light the south part of the island. If Mr. Edison has succeeded in replacing carbon he may have turned the flank of the difficulty to a certain extent.

Although, however, we may pity the ignorance of those who act upon such statements as those made by the imaginative New York Sun, gas companies may well begin to feel uneasy at the general attention which is being drawn to the electric light as a substitute for gas if they are prepared to let things alone. That in one form or other it is likely to be partially adopted in all large cities and at extensive public works seems most likely. It will be one of the lights of the future, but not to the excluding or superseding of gas-light.

Our own columns have repeatedly borne testimony to the success which has attended its introduction into Paris, where it is to be met with at almost every corner, and at one or more of the railway stations. The general testiinony of those who are unprejudiced is that at least for wide streets, squares, and open places, its lighting effect is all that could be desired. Every Londoner is familiar with the effect of the display which the enterprising $\mathrm{Mr}$. Hollingshead has placed in front of the Gaiety Theatre, and the glowing contrast presented to the miserable yellow flames of the neighbouring street-lamps; but this contrast exists because the gas is bad and dear. Mr. Hollingshead, in a letter to the Daily News, corrects the view of the gas companies, that the electric light must necessarily cost more to produce than gas. His own display, necessarily wasteful, costs four-fifths what gas would, and he is probably correct in saying that with proper management it need not cost more than one half. Moreover, in yesterday's Times, Mr. E. J. Reed refers to the case of M. E. Manchon, a large manufacturer at Rouen, who has gone to considerable expense to alter his premises to suit the electric light, and who, even with hired engine power, finds that there is an annual saving of 22.6 per cent. over gas, with infinitely better light and a wholesome atmosphere. Mr. Reed is of opinion that even if the electric light cost more than gas, its advantages are so great, that for the lighting of public places, museums, art galleries, manufactories, \&c., he would advocate its general introduction. Even Madrid, one of the most backward cities in Europe, has introduced the light, one great benefit of which, especially in theatres and other much frequented places, is that the heat generated and the contamination of the air is greatly less than in the case of gas.

Let the directors of gas companies do all they can to improve their gas. They may be certain that it will never cease to be required; a considerable splitting up of the electric current is impossible, while the brilliant light that we shall always get when electricity is employed will gradually so raise the pitch of illumination that more gas than ever will be used.

\section{THE MEDICAL FACULTIES}

$\mathrm{THE}$ opening addresses of the various London medical schools always form an interesting episode in the scientific year, and this session they have been even more interesting and have attracted more attention than usual. This is especially the case with the vigorous and trenchant address (published in full in the British Medical Journal of October 5) of Prof. Ray Lankester. On another page we reprint a remarkable article from the Lancet, in which it is plainly stated that without endowment of research the progress of medicine must soon become impossible in this country; that the work of scientific investigation demands practically the whole energies of a competent man and is incompatible with the necessity of earning a living in any other direction. It is somewhat remarkable that such an article should be published simultaneously with the outspoken address of Prof. Lankester; who aimed to show that the great Universities of this country are faithless to their duty and to the end for which they were established, in not providing for the pursuit of scientific research, in so far at least as that bears on the healing art.

"The work of the medical profession-its function in the community"-he showed, "is to bring into practical use an inmense mass of accurate knowledge with regard to the conditions affecting the healthy working of the human body. Accordingly, two distinct kinds of activity-one dependent on the other, one as important as the otherare to be recognised as essential to the business of the medical profession. The one consists in the accumulating of knowledge relating to the human body and to the conditions affecting its health, the sifting of false from true knowledge, the producing of new knowledge; the other consists in the application of this knowledge to particular cases of disease or danger in such a way that action may be taken, avoiding the disease or danger, or alleviating the suffering which results from them.

"There is a most mischievous notion current at the present time," Mr. Lankester went on, "that the first of these lines of work is 'theoretical,' and that the second is 'practical;' and it is not unusual to separate the 'theoretical' from the 'practical' man, 